\title{
EDITORIAL
}

\section{El coronavirus y la crisis de la medicina}

\author{
Diego Herrera[1]
}

1. Saludesa, Ecuador

Doi: https://doi.org/10.23936/pfr.v5i1.146

PRÁCTICA FAMILIAR RURAL | Vol.5 | No.2 | Julio 2020 | Recibido: 20/07/2020 | Aprobado: 24/07/2020

\author{
Cómo citar este artículo \\ Herrera, D. El coronavirus y la crisis de la medicina. Práctica Familiar Rural. 2020 \\ julio; 5(2).
}

\section{Resumen}

La epidemia del Covid 19, tiene un componente mediático sin antecedentes en la historia de la medicina, esto sumado a la falta de liderazgo de gobiernos e instituciones especializadas, ha generado miles de voces con mensajes equívocos, generados a partir de experiencias personales y no de un método científico. El presente editorial es un llamado de atención ante la ineficacia mostrada en la toma de decisiones e implementación de políticas sanitarias, las que han sido tomadas al calor del momento.

Palabras clave: coronavirus, política sanitaria, medios de comunicación, redes sociales.

\section{Coronavirus and the crisis of medicine}

\begin{abstract}
The Covid 19 epidemic has an unprecedented media component in the history of medicine, this added to the lack of leadership of governments and specialized institutions, has generated thousands of voices with equivocal messages, generated from personal experiences and not from a scientific method. This editorial is a wake-up call to the ineffectiveness shown in
\end{abstract}


decision-making and implementation of health policies, which have been taken in the heat of the moment.

Keywords: coronavirus, health policy, media, social media.

En medio de la crisis mundial provocada por el coronavirus, surgen en las redes sociales mentiras que incluyen, alertas e informaciones falsas emitidas por falsos microbiólogos, desconocidos expertos, millonarios y famosos del mundo, todos ellos, construyen relatos de todo tipo. Se trata de un experimento de control social, es un arma biológica, los débiles deben morir para el triunfo de los fuertes, la tierra ya no nos pertenece, este es el fin del capitalismo, y en la parte médica, la cura es un viejo fármaco o un químico sin ninguna evidencia, la medicina natural es la respuesta, a mí me funciona un coctel de fármacos que incluyen, antibióticos, antivirales, antiparasitarios y antiinflamatorios, son algunas de las noticias con las que nos "bombardean" todos los días, en medio de esta tormenta de noticias falsas, cada quien, elige la narrativa que más lo representa.

Una pregunta que surge frente a la avalancha de desinformación es ¿Tiene una voz en estas narrativas la medicina? Creemos que no, los medios están organizando la narrativa sanitaria de la pandemia y las instituciones médicas solo le hacen el juego.

La verdad es que todos hablan, pero nadie escucha a los que saben, o peor aún, cuando entrevistan a los que supuestamente saben, estos en realidad no saben. El resultado es miles de recomendaciones desde la experiencia y la pseudo ciencia en los medios de comunicación y las redes sociales.

Lo único que es común de todas estas narrativas es la utilización de la metáfora de la guerra refiriéndose al virus como un enemigo de la humanidad contra el cual estamos en la madre de todas las guerras y los médicos somos la primera línea de batalla, la metáfora es inadecuada y además ingenua, Sun Tzu aconseja en al Arte de la Guerra. "si te conoces a ti mismo, pero no conoces al enemigo, por cada batalla ganada perderás otra; si no conoces al enemigo ni a ti mismo, perderás cada batalla"

Boaventura de Sousa, cuestiona la metáfora guerrera y prefiere utilizar la metáfora del aprendizaje y escribe

Para mí el virus es un pedagogo, utiliza una pedagogía cruel, ya que si bien nos está impidiendo vivir nuestra vida como la habíamos imaginado, nos está enseñando mucho y sería muy importante que pudiéramos aprovechar este momento para ver lo que nos está intentando decir, por ejemplo, que el modelo de desarrollo que hemos seguido hasta ahora es totalmente equivocado (1).

El conocimiento se construye en el debate científico, las hipótesis se formulan y luego se invalidan o confirman, a esto llamamos método científico, sobre el cual la Medicina Occidental ha intentado posesionarse como ciencia desde Hipócrates, pero ¿qué pasa cuando perdemos el rumbo y nos vemos atrapados por los medios de comunicación y su vorágine de noticias frescas y nuevas?

La intervención de los medios de comunicación, tiende a transformar el debate científico en debate público y a difuminar la pequeña línea divisoria entre lo político y lo técnico, lo cual incrementa el riesgo de error.

Cualquier científico puede estar equivocado y ser llevado a revisar sus hipótesis para mejorar su trabajo. Así es como los diferentes grupos terminan convergiendo. Por lo tanto, es normal que haya muchas preguntas, diferentes enfoques y debates, todo esto es parte del proceso científico. En los actuales momentos no está permitido revisar ni cuestionar hipótesis, la urgencia de entregar resultados esperanzadores obliga a las 
ciencias de la salud a promover expectativas erradas, difundidas por redes sociales, que son aprovechadas políticamente sin importar el costo que las comunidades están pagando.

\section{Los errores cometidos en el camino}

Desde el inicio de la epidemia cometimos errores. En noviembre del año pasado, el Director de la OMS, admitió en una entrevista que "el mundo no está preparado para la gripe pandémica, somos muy vulnerables", y que "los países con sistemas de salud débiles impactaran al mundo entero". Curiosamente tampoco estaba preparada la OMS.

A la OMS se le acusa de a pesar de que identificó la gravedad del problema temprano, falló en actuar en consecuencia, se trató de una falla colectiva de las instituciones sanitarias y científicas tanto de los EE.UU. como de Europa, que consideraron que este era un "problema chino" con una improbable llegada peligrosa al resto del mundo. La imparcialidad de la Organización Mundial de la Salud (OMS), se pone en duda, en este momento solo los países del tercer mundo, toman nota de sus recomendaciones. La OMS enfrentada a una crisis financiera y de credibilidad, es criticada por los sectores de izquierda, señalando sus conflictos de intereses con multinacionales y laboratorios, y también se la crítica por los sectores de derecha, por la ineficiencia de su burocracia o la supuesta influencia China o Rusia sobre sus autoridades.

El colonialismo y el patriarcado están vivos y se fortalecen en tiempos del coronavirus (1).

\section{Los datos falsos de proyecciones y simulaciones}

Los gobiernos de todo el mundo se han basado en proyecciones matemáticas para guiar sus decisiones sanitarias "para enfrentar el coronavirus", tanto a nivel nacional como a nivel local con un altísimo costo sanitario, político y económico para toda la población del mundo, pero espacialmente para los más pobres. Estamos estudiando una enfermedad que no conocemos con modelos ideados para enfermedades infecciosas ya conocidas, estos modelos han determinado confinamientos que alcanzaron a la mitad de la humanidad. Con fundamentos más o menos científicos, sus conjeturas han actuado como profecías en todo el planeta. Sin embargo, todos estos modelos fallaron y se enfrentan a la falta de datos y a un virus que para la ciencia tiene "escasez de certezas". Se estima que se utilizaron alrededor de treinta diferentes modelos, durante la crisis de la pandemia, todos dieron pronósticos muy diferentes.

El mayor ejemplo de" dudosa asertividad" es el modelo matemático del prestigioso Imperial College de Londres. El cual predijo que en ausencia de contención de la población "aproximadamente 510.000 personas morirían en el Reino Unido de COVID-19 y 2,2 millones solo en los Estados Unidos ". Al menos ocho de sus investigadores fueron miembros del Grupo Científico Asesor para Emergencias (SAGE), que asesora al gobierno del primer ministro Boris Johnson o subcomités oficiales. Sus pronósticos alarmaron al mundo, provocando la compra de millones de fundas de cadáveres y la construcción de hospitales de contención para miles de personas, hospitales de guerra sin oxígeno, sin fármacos, sin recursos humanos capacitados. El discurso político maquiavélicamente redujo la instalación de las unidades de cuidados intensivos a la compra de respiradores.

Cuando los medios de comunicación presentaban sus modelos predictivos, los médicos, nos olvidamos de las clases de epidemiologia, donde se recalcaba, que los modelos pueden tener diferentes niveles de complejidad según la pregunta de investigación, cualquier modelo es una abstracción, una simplificación de la realidad que permite comprender mejor un fenómeno, confirmar o invalidar una hipótesis. Los modelos no son bolas de cristal, son herramientas que permiten traducir hipótesis en estimaciones que luego podemos enfrentar con la realidad. 
El "elefante en la sala" que nadie quiere mirar al momento de elaborar un modelo, es el desconocimiento del comportamiento del coronavirus sumado a que los datos que tenemos de infección y de mortalidad son manipulados, debido que el estándar de oro diagnóstico, es una prueba costosa y de difícil acceso, que especialmente para las poblaciones pobres, donde nadie quiere contar las muertes fortuitas porque estas no se representan en ningún modelo utilizado por las instituciones sanitarias.

Estamos utilizando las experiencias y aprendizajes de epidemias pasadas. El nuevo coronavirus, no es gripe, ni es el SARS-CoV-1, solo el tiempo pueden mostrar cómo estas epidemias son diferentes y cómo las estrategias deben adaptarse en consecuencia, un modelo debe basarse en el conocimiento de la enfermedad. En el caso de COVID-19, es muy poco el tiempo transcurrido para conocer el comportamiento de este nuevo virus.

Jorge Paz, Investigador Principal del CONICET en Argentina, señala "Estamos estudiando una enfermedad que no conocemos con modelos ideados para enfermedades conocidas, estamos aplicando medidas de contención como si se tratara de una o varias de las enfermedades infecciosas conocidas. Lo que quiero decir con esto: no se trata de predecir la evolución de los contagios por gripe, sino de una enfermedad que desconocemos cómo se comporta".

\section{La incertidumbre sobre el uso universal de las medidas de prevención}

En los primeros meses de la pandemia, los trabajos del doctor Pascal Crépey, profesor-investigador francés, experto en influenza, sirvieron para promover la cuarentena a nivel mundial, con el objetivo de evitar la saturación del sistema de salud.

Pocos meses después la OMS público que, "aplicar medidas de cuarentena, reducen el número de enfermos en un 44-81\% y el número de defunciones en un 31-63\%, aclarando que la cuarentena sola no es suficiente, a esta se deben sumar otras medidas como cierre de escuelas y distanciamiento social" (2).

Luego de 3 meses de confinamiento, el costo económico, social y psicológico fue desbastador (3), ante la imposibilidad de mantener la cuarentena, y desechando las recomendaciones de las instituciones médicas, se idearon modelos de desconfinamiento gradual de la población por ciudades, los resultados fueron un nuevo incremento de los casos y las muertes, lo que obligo a recomendar un marco de desconfinamiento mixto (4) para proteger aquellos individuos más susceptibles a tener complicaciones por esta infección.

La parte complementaria del desconfinamiento es, la vigilancia de las tasas de transmisión mediante pruebas y rastreo de contactos, esta nunca se pudo realizar debido al poco presupuesto asignado a la emergencia en los países latinoamericanos, la escasez de recursos humanos y el limitado acceso a las pruebas biológicas, como respuesta política los gobiernos comenzaron a utilizar pruebas rápidas de dudosa eficacia tanto para la identificación de contactos como para vigilancia epidemiológica.

Las únicas recomendaciones que van quedando son el distanciamiento social, el lavado de manos y el uso universal de los tapabocas, esta última recomendación tomada del ejemplo de los países asiáticos y sus resultados al enfrentar la gripe. La evidencia dice que, "las mascarillas deben usarse como parte de una estrategia integral de medidas para suprimir la transmisión y salvar vidas". Existen mascarillas de varios tipos y todas los emprendedores están fabricando su versión de tapabocas N95. La población carente de recursos, está utilizando mascarillas de tela, la OMS afirma que estas mascarillas tienen" evidencia limitada de su efectividad" y no recomienda su uso masivo como control del covid-19, controversialmente si las recomienda en las áreas que existe poca capacidad para tomar medidas de control, o se hace difícil el distanciamiento físico, como en el transporte público, tiendas y ambientes concurridos, las autoridades deben fomentar el uso de tapabocas de tela (5), (6). 
Sin embargo, el uso de mascarillas amerita un uso correcto y un alto cumplimiento de la recomendación, lo que se convierte en un gran desafío, especialmente para las personas de escasos recursos económicos. Estudios señalan la baja adherencia a la recomendación del uso de la mascarilla facial en el entorno comunitario, en las comunidades pobres. (7), (8).

Gran parte de la población mundial no está en condiciones de seguir las recomendaciones de la Organización Mundial de la Salud para defenderse del virus, ya que vive en espacios reducidos o muy contaminados, está obligada a trabajar en condiciones de riesgo para alimentar a sus familias, está detenida en cárceles o en campos de internamiento, no tiene jabón ni agua potable, o la poca agua disponible es para beber y cocinar (1).

En otros contextos, están los trabajadores de la salud, el personal de limpieza de los hospitales, el personal de seguridad, los agentes de tránsito, las personas "uberizadas" de la economía informal que entregan alimentos y paquetes a domicilio. Ellos son los que garantizan la cuarentena de muchos, pero no pueden protegerse.

Las pandemias no matan tan indiscriminadamente como se cree, el virus no es democrático, no todos pueden quedarse en casa o protegerse y la mortalidad es mayor en los ancianos, los pobres y los que carecen de atención medica de tercer nivel.

\section{La debilidad de la evidencia publicada en revistas prestigiosas}

Otra crisis de credibilidad, viven las grandes revistas médicas, en pocos meses se publicaron estudios que se convirtieron en políticas nacionales de salud, estudios que fueron cuestionados y retirados por carecer de rigor científico, dos estudios publicados en las prestigiosas revistas New England Journal of Medicine y The Lancet se retiraron porque se basaron en una base de datos no independiente. El estudio NEJM examinó la relación entre los medicamentos para la hipertensión y la mortalidad en pacientes con COVID-19, mientras que el estudio Lancet analizó si la hidroxicloroquina y la cloroquina eran tratamientos efectivos con COVID-19.

Uno de los primeros fármacos utilizados para el tratamiento de Sars Cov 2, en todo el mundo, fue la azitromicina basados en un estudio publicado en el Journal of Antimicrobial Agents(11).

A los pocos meses otro estudio publicado recientemente en JAMA demostró que la azitromicina y la hidroxicloroquina, no disminuían la mortalidad de los pacientes hospitalizados (12).

Al mismo tiempo se publicó un estudio in vitro que aseguraba que la Ivermectina inhibía el crecimiento del virus, respaldada por dos estudios no publicados y sin revisión de pares, rápidamente fueron utilizados políticamente para justificar la administración de este antiparasitario a pobladores en varios países de Latinoamérica (9-10)

\section{A manera de conclusión}

Una historia en aprendizaje de la incertidumbre, es lo que necesitan las sociedades médicas, que incluyan aceptar las múltiples posibilidades que nos da miedo reconocer a los médicos en la parte sanitaria que la epidemia se va transformando en una endemia, que las medidas de protección no están logrando su objetivo, que no solo se presente una segunda ola, sino que se transforme en una infección estacional.

En los aspectos clínicos que el virus no se parece a ninguna enfermedad infecciosa antes conocida, que en lo clínico es un gran simulador y está obligándonos a repensarlas enfermedades que creíamos conocer, que algunos pacientes pueden desarrollar síntomas crónicos, que no sabemos cuál es el tratamiento. 
La tarea de la ciencia, es realizar una lectura crítica de todo lo publicado y retomar el método científico, con humildad reconocer nuestro desconocimiento sobre esta nueva enfermedad, cuestionando todo lo publicado, y denunciando las actuaciones políticas disfrazada de evidencia medica que se recomiendan a alto costo a la población.

Solo mediante una nueva articulación entre los procesos políticos y civilizadores será posible comenzar a pensar en una sociedad en la que la humanidad asuma una posición más humilde en el planeta en el que habita. (1)

\section{Referencias bibliográficas}

1. Booventura Sousa Santos, La cruel Pedagogía del Virus, CLACSO, Buenos Aires, 2020.

2. Nussbaumer-Streit B, Mayr V, Dobrescu AIulia, Chapman A, Persad E, Klerings I, Wagner G, Siebert U, Christof C, Zachariah C,Gartlehner G. Quarantine alone or in combination with other public health measures to control COVID-19: a rapid review. Cochrane Database of Systematic Reviews 2020, Issue 4. Art. No.: CD013574. DOI: 10.1002/14651858.CD013574

3. Mia, A., Griffiths, M. Letter to the Editor: The economic and mental health costs of COVID-19 to $\begin{array}{lllll}\text { immigrants, Journal of } & \text { Psychiatric } & \text { Research } & 128 & \text { (2020) }\end{array}$ https://doi.org/10.1016/j.jpsychires.2020.06.003

4. British Lung Foundation. Coronavirus and COVID-19: What is social shielding and who needs to do this? 2020. Disponible en: https://www.blf.org.uk/support-for-you/coronavirus/what-is-socialshielding

5. Organización Mundial de la Salud. Recomendaciones sobre el uso de mascarillas en el contexto de la COVID-19: orientaciones provisionales, 6 de abril de 2020. Organización Mundial de la Salud. https://apps.who.int/iris/handle/10665/331789. License: CC BY-NC-SA 3.0 IGO)

6. Mingming Lianga,Liang Gaoc,Ce Cheng, Qin Zhoue,and others,Efficacy of face mask in preventing respiratory virus transmission: A systematic review and meta-analysis, Travel Medicine and Infectious Disease, May, 2020

7. (Cowling BJ, Fung RO, Cheng CK, Fang VJ, Chan KH, Seto WH, et al. Preliminary findings of a randomized trial of non-pharmaceutical interventions to prevent influenza transmission in households. PloS One 2008;3:e2101https://doi.org/10. 1371/journal.pone.0002101.)

8. Cowling BJ, Chan K, Fang VJ, Cheng CK, Fung RO, Wai W, et al. Facemasks and hand hygiene to prevent influenza transmission in households: a cluster randomized trial. Ann Intern Med 2009;151:437-46)

9. Caly L, Druce JD, Catton MG, Jans DA, Wagstaff KM. The FDA-approved drug ivermectin inhibits the replication of SARS-CoV-2 in vitro. Antiviral Res. 2020;178:104787. doi:10.1016/j.antiviral.2020.104787

10. Chaccour C, Hammann F, Ramón-García S, Rabinovich NR. Ivermectin and COVID-19: Keeping Rigor in Times of Urgency. Am J Trop Med Hyg. 2020;102(6):1156-1157. doi:10.4269/ajtmh.20-0271

11. Gautret, P., Lagier, J.C., Parola, P., Meddeb, L., Mailhe, M., Doudier, B., Courjon, J., Giordanengo, V., Vieira, V.E., Dupont, H.T. and Honoré, S., 2020. Hydroxychloroquine and azithromycin as a treatment of COVID-19: results of an open-label non-randomized clinical trial. International Journal of Antimicrobial Agents, p.105

12. Rosenberg ES, Dufort EM, Udo T, et al. Association of Treatment With Hydroxychloroquine or Azithromycin With In-Hospital Mortality in Patients With COVID-19 in New York State [published online ahead of print, 2020 May 11]. JAMA. 2020;323(24):2493-2502. doi:10.1001/jama.2020.8630 